(c) 2015. This manuscript version is made available under the CC-BY-NC-ND 4.0 license http://creativecommons.org/licenses/by-nc-nd/4.0/

\title{
Theoretical Approach to Predict Transverse Impact Response of Variable-Stiffness Curved Composite Plates
}

\author{
B. Arachchige, H. Ghasemnejad ${ }^{1}$, A.T. Augousti \\ ${ }^{1}$ School of Aerospace and Aircraft Engineering, Kingston University London, \\ SW15 3DW UK
}

\begin{abstract}
This research studies the low velocity impact behaviour of variable stiffness curved composite plates. Since variable thickness within composite structures is recognised as an important factor on the performance of the structures, significant mathematical modelling to predict the impact response of these types of structure is essential. Varying thicknesses of sections is widely found in aerospace and automotive composite sub structures. It has been observed that changing of geometry of these sections can vary the dynamic response of anisotropic composite structures under a range of monolithic and dynamic loading conditions. Here we have used first order shear deformation theory to predict the contact force history of curved composite plates and the same approach was used for variable thickness composite plates, which provides the main novelty of this research. It was shown that the model developed here is capable of successfully predicting the response of variable stiffness composite plates with a range of layups and geometry designs under impact loading conditions.
\end{abstract}

Keywords: A. Polymer-matrix composites (PMCs); B. Impact behaviour; B. Variable stiffness; C. Analytical modelling;

\footnotetext{
${ }^{1}$ Corresponding Author: email: Hessam.Ghasemnejad@kingston.ac.uk Tel.:+44 2085174738.
} 


\section{Nomenclature}

E Young's modulus (GPa)

$F(t) \quad$ dynamic force

$G_{12} \quad$ shear modulus (GPa)

$h \quad$ thickness

$t \quad$ beam thickness $(\mathrm{mm})$

$R \quad$ radius

$\gamma \quad$ Poisson's ratio

$\rho \quad$ density

$\mathrm{M}_{1} \quad$ mass of plate

$\mathrm{M}_{2} \quad$ mass of striker

K1 stiffness constant of plate

K2 stiffness constant of striker

$K_{2}^{*} \quad$ effective contact stiffness

V impact velocity

$u, v, w \quad$ displacements in $\mathrm{x}, \mathrm{y}, \mathrm{z}$ coordinate systems

$x, \theta, z \quad$ axial, circumferential and radial coordinates for a curved shell

$k \quad$ Mindlin shear correction factor

$\beta_{x}, \beta_{y} \quad$ bending slopes in the $x-z$ and $\theta-z$ planes

$N_{x}, N_{\theta}, N_{x \theta}$ in surface stress resultants in cylindrical polar system

$M_{x}, M_{\theta}, M_{x \theta}$ bending and twisting moments per unit length

$q_{x}, q_{\theta} \quad$ surface load components along the axial $\mathrm{x}$-axis $\&$ circumferential $\theta$ axes

$A_{i j}, D_{i j} \quad$ extensional, bending stiffness of a laminated shell

$Q_{x}, Q_{\theta} \quad$ transverse shearing force per unit length 


\section{Introduction}

The use of composite materials in aerospace and automotive structures has greatly increased in the last decades as a result of their attractive structural properties. Beneficial properties such as low weight, high stiffness to weight ratio, high fatigue strengths and good corrosion and impact resistance are the most highlighted characteristics of these materials. It has been shown that failure modes of composite structures under low-velocity impact loading conditions are strongly dependent on the fibre type, resin type, lay-up, thickness, loading velocity and projectile type [1].

Many researchers have investigated different mathematical models to predict the impact behaviour of various composite materials and structures. Some of these models which are used to study the impact behaviour of composite structures by external objects are briefly discussed below.

Chai and Zhu [2] reviewed the numerical, mathematical and experimental methods used for the analysis of sandwich panels subjected to impact loading. They analysed the impact responses according to the main parameters, and consequently identified different classes of impact. The impact responses on sandwich structures were broadly categorised into two main groups, high-velocity and low-velocity impacts, with the focus on the low velocity impact. Khalili et al [3] developed an analytical model to predict the impact force history which compared well with the experimental and analytical results in the literature. Their results showed that the stacking sequence of the face sheet has an insignificant effect on both the impact force and the contact duration. They also showed that if the case of zero in-plane forces is considered as a reference state, then positive in-plane forces increase the impact force and decrease the contact duration, while negative in-plane forces produce exactly the opposite effects, namely decreasing the impact force and increasing the contact duration. In another paper [4] they studied the dynamic response of a thin smart curved composite panel subjected to a low-velocity transverse impact. In their work shape memory alloys were used to reinforce the curved composite panel. A one-dimensional thermodynamic constitutive model by Liang and Rogers [ref] is used for estimating the structural recovery stress. 
Shivakumar et al. [5] used a two-degrees-of-freedom model that consisted of four springs for bending, shear, membrane and contact rigidities to predict the impact response of a circular plate. In this model, the contact force and the contact duration for low-velocity impact on circular laminates was calculated. Gong and Lam [6] used a spring-mass model having two degrees-of-freedom in order to determine the history of the contact force produced during impact. They included structural damping also in their model. Gong et al. [7] studied the elastic response of orthotropic laminated cylindrical shells to low-velocity impact. A spring-mass model was developed to determine the contact force between the shell and the striker. An analytical function for the contact force was derived in terms of material properties and the mass of the shell and the striker, as well as for the impact velocity. Caprino et al. [8] used a single degree-of-freedom system to analyse drop weight impact tests on glass/polyester sandwich panels. Anderson [9] described an investigation using a single degree-offreedom model for large mass impact on composite sandwich laminates. The stiffness parameters of the model were derived from the results of a three-dimensional quasistatic contact analysis of a rigid sphere indenting a multi-layered sandwich laminate.

Nanda and Kapuria [10] showed that the orthotropic ratio of the composite has a significant effect on the wavenumbers for tangential and mid-surface rotation modes. The wave propagation response predicted by the classical laminate theory (CLT) differs widely from the first-order shear deformation theory (FSDT) prediction, for thin and thick, and shallow and deeply curved beams at both low and high frequencies. Thus, the CLT should not be used for wave propagation analysis of even thin curved laminated beams. More recently, Kavousi Sisi et al [11] presented a theoretical method for low-velocity impact analysis of composite laminated beams with arbitrary lay-ups and various boundary conditions subjected to asynchronous/repeated impacts of multiple masses. Their results showed that the time of impact plays an important role in determining contact forces, beam displacements, absorbed energies by the beam and normal and shear stresses by positive and negative superposition of induced waves. Dinh Duc $[12,13]$ investigated an analytical method for calculating the nonlinear dynamic response of eccentrically stiffened functionally graded double curved shallow shells resting on elastic foundations and being subjected to axial compressive load and transverse load. The non-linear equations were solved by the Runge-Kutta and Bubnov-Galerkin methods and their results 
characterised the effects of material and geometrical properties, elastic foundation and imperfection on the dynamical response of reinforced FGM shallow shells. Li et al [14] studied low-velocity impact responses and impact-induced damage evaluation problems for the stiffened composite laminated plates based on the progressive failure model and layerwise/solid elements method (LW/SE). Ghasemnejad et al $[15,16]$ studied the Charpy impact behaviour of single and multi-delaminated hybrid composite beam structures. The Charpy impact test was chosen to study the energy absorption capability of a delaminated composite beam. It was shown that the composite beams with the position of delamination closer to the impacted surface are able to absorb more energy in comparison with other delamination positions in hybrid and non-hybrid ones.

Despite of all these research contributions which have investigated a range of theoretical models in order to study the dynamic and transient responses of composite structures, the effect of geometric changes in terms of variable layups (stiffness) within a composite structure remains an area that still requires further investigations. This research reports the development of a new mathematical model and to employ this to predict the impact response of curved composite panels with variable stiffness determined by thickness. A spring-mass model was used to predict the contact force between a striker and a curved plate with variable stiffness during an impact event. The effect of various parameters including layups, impact velocity and geometric change were investigated in the research reported here.

\section{Theoretical formulations}

The solution to the dynamic problem is presented in the form of expansions of the loads, displacement, and rotation functions as double Fourier series [7]. Each expression is based on a function of position and a function of time. Love's equations of motion for a curved shell of dimensions $a$ and $b$, radius $\mathrm{R}$ and thickness $\mathrm{h}$ under external loads [7] are expressed as (Figure 1):

$$
\begin{aligned}
& \frac{\partial N_{x}}{\partial x}+\frac{1}{R} \frac{\partial N_{x \theta}}{\partial \theta}+q_{x}(x, \theta, t)=\rho h \ddot{u} \\
& \frac{\partial N_{x \theta}}{\partial x}+\frac{1}{R} \frac{\partial N_{\theta}}{\partial \theta}+\frac{Q_{\theta}}{R}+q_{\theta}(x, \theta, t)=\rho h \ddot{v}
\end{aligned}
$$


$\frac{\partial Q_{x}}{\partial x}+\frac{1}{R} \frac{\partial Q_{\theta}}{\partial \theta}-\frac{N_{\theta}}{R}+q_{n}(x, \theta, t)=\rho h \ddot{w}$

$\frac{\partial M_{x}}{\partial x}+\frac{1}{R} \frac{\partial M_{x \theta}}{\partial \theta}-Q_{x}=\frac{\rho h^{3}}{12} \ddot{\beta}_{x}$

$$
\frac{\partial M_{x \theta}}{\partial x}+\frac{1}{R} \frac{\partial M_{\theta}}{\partial \theta}-Q_{\theta}=\frac{\rho h^{3}}{12} \ddot{\beta}_{\theta}
$$
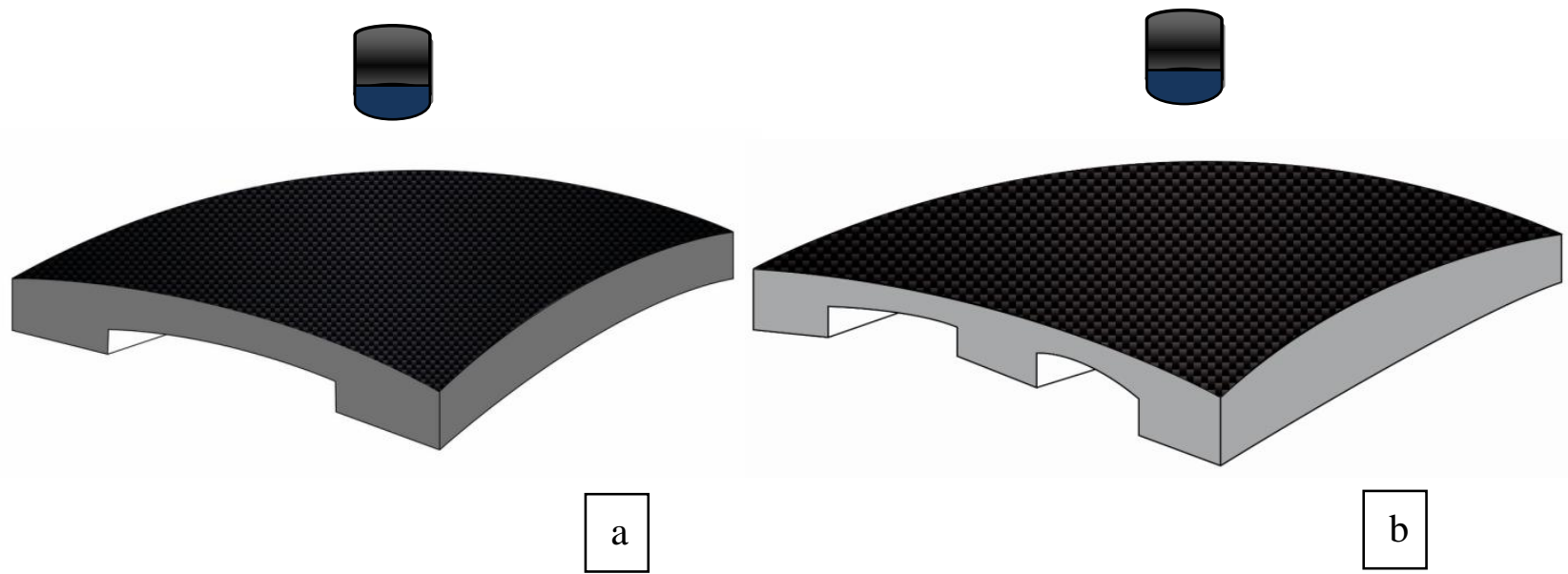

Fig. 1. The schematic curved composite plate with variable thickness (stiffness), a) three sectioned curved plate and b) five sectioned curved plate.

The constitutive equations of an especially orthotropic material are described as:

$$
\begin{aligned}
& \left\{\begin{array}{l}
N_{x} \\
N_{\theta} \\
N_{x \theta}
\end{array}\right\}=\left[\begin{array}{ccc}
A_{11} & A_{12} & 0 \\
A_{12} & A_{22} & 0 \\
0 & 0 & A_{66}
\end{array}\right]\left\{\begin{array}{c}
\varepsilon_{x}^{0} \\
\varepsilon_{\theta}^{0} \\
\gamma_{x \theta}^{0}
\end{array}\right\} \\
& \left\{\begin{array}{l}
M_{x} \\
M_{\theta} \\
M_{x \theta}
\end{array}\right\}=\left[\begin{array}{ccc}
D_{11} & D_{12} & 0 \\
D_{12} & D_{22} & 0 \\
0 & 0 & D_{66}
\end{array}\right]\left\{\begin{array}{c}
\kappa_{x} \\
\kappa_{\theta} \\
\kappa_{x \theta}
\end{array}\right\} \\
& \left\{\begin{array}{l}
Q_{x} \\
Q_{\theta}
\end{array}\right\}=\left[\begin{array}{cc}
k A_{55} & 0 \\
0 & k A_{44}
\end{array}\right]\left\{\begin{array}{l}
\gamma_{x z}^{0} \\
\gamma_{\theta z}^{0}
\end{array}\right\}
\end{aligned}
$$

where,

$$
\left\{A_{i j}, D_{i j}\right\}=\int_{-h / 2}^{h / 2} \bar{Q}_{i j}\left(1, z^{2}\right) d z \quad(\mathrm{i}, \mathrm{j}=1,2,6)
$$


$\bar{Q}_{i j}$ are the transformed reduced stiffness in the $x-\theta$ plane, $\bar{C}_{i i}$ are the transformed shear stiffness, and $k$ is the Mindlin shear correction factor which is $\pi^{2} / 12$ [7].

The strain-displacement relations are expressed as:

$\varepsilon_{x}^{0}=\frac{\partial u}{\partial x} \quad \varepsilon_{\theta}^{0}=\frac{1}{R} \frac{\partial v}{\partial \theta}+\frac{w}{R} \quad \gamma_{x \theta}^{0}=\frac{\partial u}{\partial x}+\frac{1}{R} \frac{\partial u}{\partial \theta}$

$\kappa_{x}=\frac{\partial \beta_{x}}{\partial x} \quad \kappa_{\theta}=\frac{1}{R} \frac{\partial \beta_{\theta}}{\partial \theta} \quad \kappa_{x \theta}=\frac{\partial \beta_{0}}{\partial x}+\frac{1}{R} \frac{\partial \beta_{x}}{\partial \theta}$

$\gamma_{x z}^{0}=\beta_{x}+\frac{\partial w}{\partial x} \quad \gamma_{\theta z}^{0}=\beta_{\theta}+\frac{1}{R} \frac{\partial w}{\partial \theta}-\frac{v}{R}$

Double Fourier series, for the displacements and the rotation of rectangular doubly curved composite panel with simply supported boundary conditions are defined according to:

$w_{0}\left(x_{1}, x_{2}, t\right)=\sum_{i=1}^{\infty} \sum_{j=1}^{\infty} W_{m n}(t) \sin \frac{i \pi x_{1}}{a} \sin \frac{j \pi x_{2}}{b}$

For a concentrated load located at the point,

$Q_{i j}(t)=\frac{4 F(t)}{a b} \sin \frac{i \pi x_{c}}{b} ; i, j=1,3,5, \ldots$

$\ddot{W}_{i j}(t)+\omega_{i j}^{2}(t)=\frac{Q_{i j}(t)}{\rho h}$

The natural frequency of the plate is given by;

$\omega_{i j}^{2}=\frac{-\left(c_{13} K_{U}+c_{23} K_{V}+c_{33}+c_{34} K_{X}+c_{35} K_{Y}\right)}{\rho h}$

A definition of all the constants in the equation above can be found in [4]

$W_{i j}(t)+\omega_{i j}^{2} W_{i j}(t)=\frac{4 F(t)}{a b \rho h} \cos \frac{i \pi x_{c}}{a} \cos \frac{j \pi \theta_{c}}{b}$

For a zero initial displacement and velocity of the curved panel, the solution becomes:

$W_{i j}(t)=\frac{1}{\omega_{i j}} \frac{4}{b \rho \rho h} \cos \frac{i \pi x_{c}}{a} \cos \frac{j \pi \theta_{c}}{b} \int_{0}^{t} F(\tau) \sin \omega_{i j}(t-\tau) d \tau$ 
In the springs-masses model, $\mathrm{M}_{1}$ and $\mathrm{M}_{2}$ represent the mass of the shell and the striker respectively; $K_{1}$ is the constant stiffness of the shell and $K_{2}$ is the stiffness of the striker. The stiffness of the simply supported laminated shell can be defined as:

$K_{1}=\omega_{1}^{2} M_{1}$

where, $\omega_{1}$ is the fundamental frequency of the laminated shell and obtained through equation (17) by applying $i=j=1$.

If $z_{1}(t)$ represent the radial displacement of the load point of the shell and $z_{2}(t)$ represent the striker movement at any time $t$ during the impact, then the contact deformation is expressed as (see Figure 2):

$\partial(t)=z_{2}(t)-z_{1}(t)$

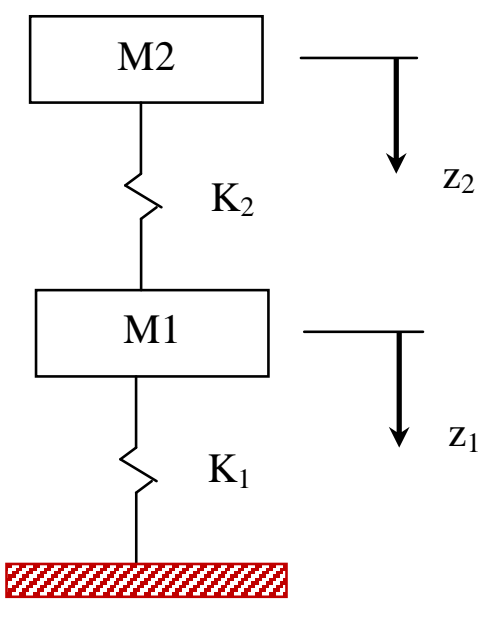

Fig. 2. Two-degrees-freedom of spring-mass system to model dynamic force.

Therefore, the existing approach applies effective contact stiffness $K_{2}^{*}$ in order to relate the equivalent contact force to the contact deformation.

$F_{c}^{*}(t)=K_{2}^{*} \partial$

which can also be expressed as,

$F_{c}^{*}(t)=K_{2}^{*}\left[z_{2}(t)-z_{1}(t)\right]$ 
The effective contact stiffness $K_{2}^{*}$ is calculated as [7]:

$K_{2}^{*}=\sqrt{\pi} \Gamma\left(\frac{p+1}{2}\right) \frac{2 \Gamma\left(\frac{p}{2}+1\right)+\sqrt{\pi} \Gamma\left(\frac{p+1}{2}\right)}{4 \Gamma^{2}\left(\frac{p}{2}+1\right)+\pi \Gamma^{2}\left(\frac{p+1}{2}\right)} \delta_{m}^{p-1} K_{2}$

where $\Gamma$ is the Gamma function and the maximum contact deformation, $\partial_{m}$ is given by:

$\left(\frac{M_{1} M_{2}}{M_{1}+M_{2}}\right)^{0.4}\left[\frac{5 V^{2}}{4 k_{2}}\right]^{0.4}<\partial_{m}<\left(M_{2}\right)^{0.4}\left[\frac{5 V^{2}}{4 k_{2}}\right]^{0.4}$

This study involves a target structure with simply supported edges and $\partial_{m}$ for the simply supported target structure is expressed as:

$\left(\partial_{m}\right)_{f}<\left(\partial_{m}\right)_{s s}<\left(\partial_{m}\right)_{c}$

where the subscripts $f, s s, c$ refer to free, simply supported and clamped respectively. The corresponding equations of motion for a two-degree-of-freedom $(2 \mathrm{df})$ model are as follows:

$m_{1} \ddot{z}_{1}=-k_{1} z_{1}-k_{2}\left(z_{1}-z_{2}\right)$

$m_{2} \ddot{z_{2}}=-k_{2}\left(z_{2}-z_{1}\right)$

The initial conditions are defined as:

$z_{1}=z_{2}=0, \quad z_{2}=V \quad$ at $t=0$

By using the initial conditions defined in Eq. 21 the analytical function for the force can be defined as:

$F_{c}^{*}(t)=K_{2}^{*}\left[A_{1}\left(C_{1}-1\right) \sin \omega_{1} t+A_{2}\left(C_{2}-1\right) \sin \omega_{2} t\right]$ 
The coefficients in the analytical function for the force are derived as

$C_{1}=\frac{k_{2}}{k_{2}-\omega_{1}^{2} M_{2}}$

$C_{2}=\frac{k_{2}}{k_{2}-\omega_{2}^{2} M_{2}}$

$A_{1}=\frac{V}{\omega_{1}\left(C_{1}-C_{2}\right)}$

$A_{1}=\frac{V}{\omega_{2}\left(C_{2}-C_{1}\right)}$

Finally, by substituting all coefficients of Eqs. (14), (21) and (28) into Eq. (27), the dynamic force can be found as:

$$
\begin{aligned}
& F(t)= \\
& {\left[\sqrt{\pi} \Gamma\left(\frac{p+1}{2}\right) \frac{2 \Gamma\left(\frac{p}{2}+1\right)+\sqrt{\pi} \Gamma\left(\frac{p+1}{2}\right)}{4 \Gamma^{2}\left(\frac{p}{2}+1\right)+\pi \Gamma^{2}\left(\frac{p+1}{2}\right)} \delta_{m}^{p-1} K_{2}\right]\left[\begin{array}{c}
\frac{A_{1}\left(C_{1}-1\right)}{w_{1}^{2}-w_{i j}^{2}}\left(w_{1} \sin w_{i j} t-w_{i j} \sin w_{1} t\right) \\
+\frac{A_{2}\left(C_{2}-1\right)}{w_{2}^{2}-w_{i j}^{2}}\left(w_{2} \sin w_{i j} t-w_{i j} \sin w_{2} t\right)
\end{array}\right]}
\end{aligned}
$$

\section{Verification of the theoretical models}

The selected theoretical model was verified well with available results in the literature $[4,7]$. The model was applied to a curved steel plate and also a curved composite plate with 48-ply laminate consisting of a $[( \pm 45 / 02) 2 / \pm 45 / 0 / 90] 2$ s lay-up fabricated from graphite/epoxy prepreg. The mechanical properties and geometric dimensions can be found in Tables 1 and 2. The comparison of the force - time history showed a good agreement between present results and previous published work (see Figure 3). 


\begin{tabular}{cc}
\hline$E_{11}$ & $141.2 \mathrm{GPa}$ \\
\hline$E_{22}=E_{33}$ & $9.72 \mathrm{GPa}$ \\
\hline$G_{12}=G_{13}$ & $5.53 \mathrm{GPa}$ \\
\hline$G_{23}$ & $3.74 \mathrm{GPa}$ \\
\hline$v_{12}=v_{13}=v_{23}$ & 0.30 \\
\hline$\rho$ & $1536 \mathrm{~kg} / \mathrm{m}^{3}$ \\
\hline
\end{tabular}

Table 1. Mechanical properties of CFRP composite materials. 


\begin{tabular}{cc}
\hline$E$ (Young's Modulus) & $207 \mathrm{GPa}$ \\
\hline$v$ & 0.30 \\
\hline$\rho$ & $7800 \mathrm{~kg} / \mathrm{m}^{3}$ \\
\hline Tip diameter & $20 \mathrm{~mm}$ \\
\hline Mass of the striker & $3 \mathrm{~kg}$ \\
\hline Striker velocity & $6 \mathrm{~m} / \mathrm{s}$ \\
\hline
\end{tabular}

Table 2. Mechanical properties of steel striker.
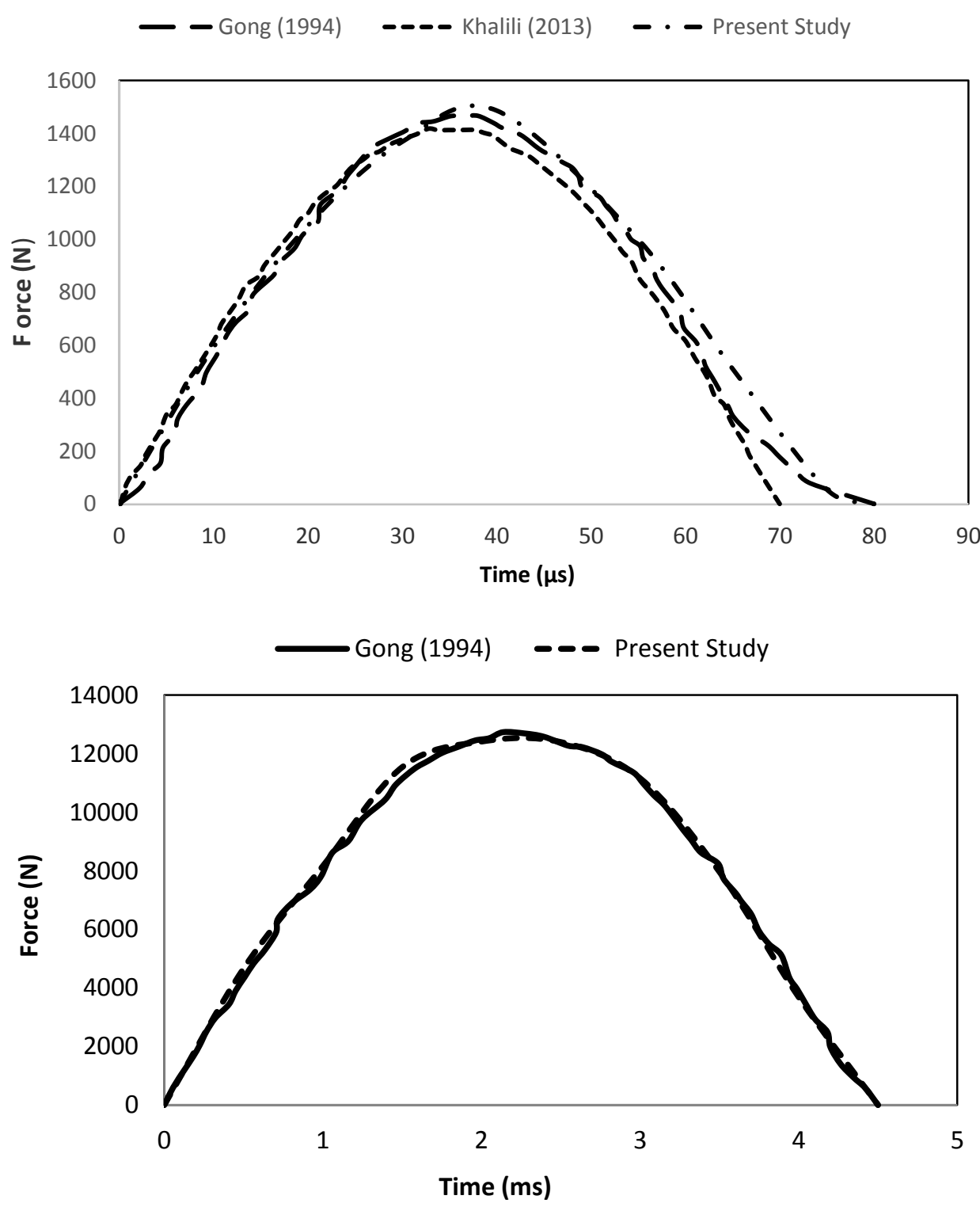

Fig. 3. a) Comparison of the force-time history for a) Steel plate and b) composite plate between the results of this work and results available in the literature. 


\section{Theoretical model for a variable stiffness curved plate}

The theoretical model in section 4 was developed for two curved composite plates with variable thicknesses across the domain (see Figure 4). The analysis is divided into two models, firstly a curved composite plate with three variable thicknesses (Figure $4 b$ ) and secondly one with five variable thicknesses (Figure 4c).

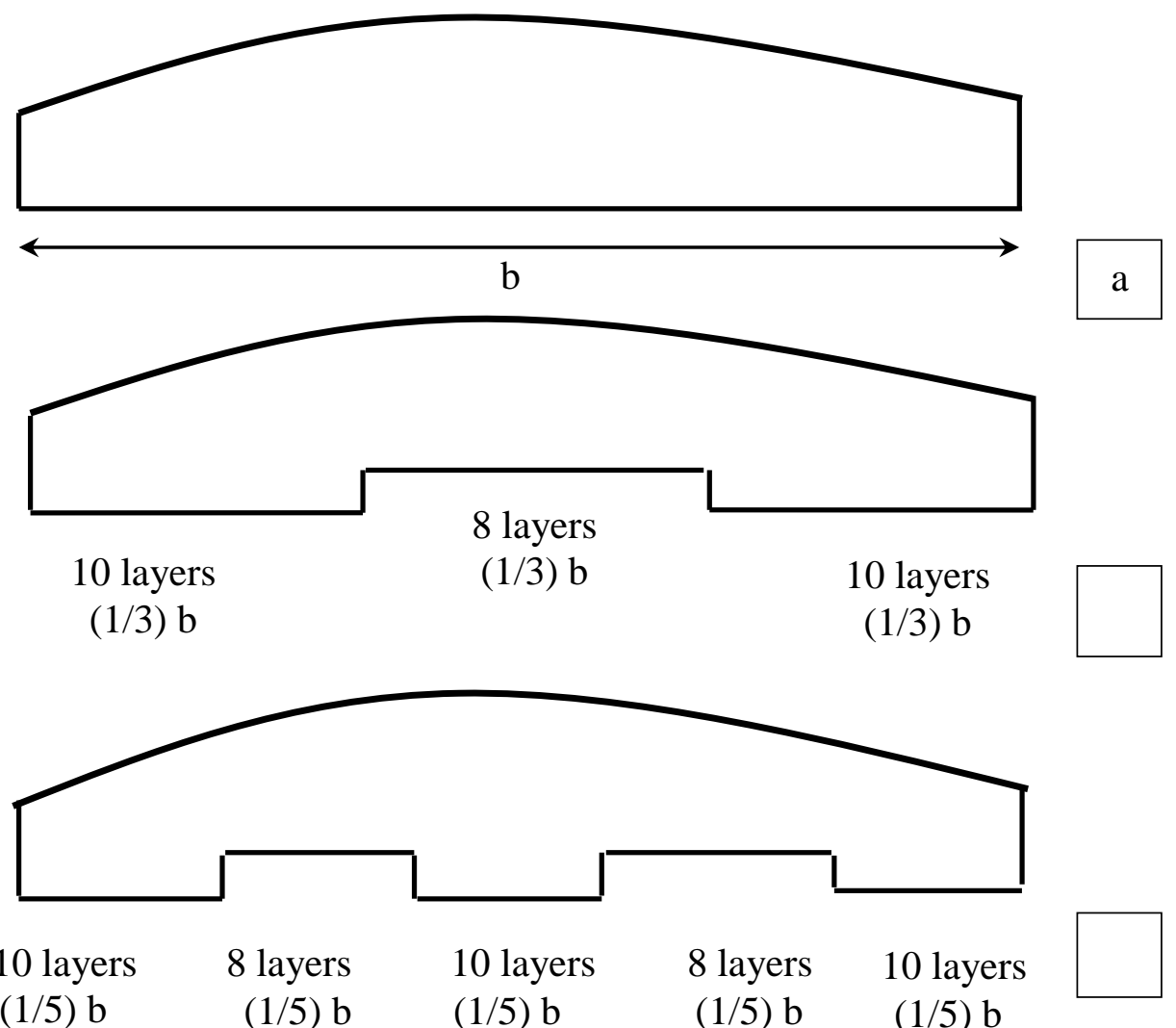

Fig. 4. Various designs of curved composite plates with a) uniform thickness, b) three variable thicknesses and c) five variable thicknesses and equal width (side view).

Each case is analysed for a range of impact velocities and laminate designs to understand their effect on the impact performance of composite structures. The proposed model is based on the natural frequency, $\omega_{e q}$ of the plate and $\omega_{1,2}$ is given as follows:

$\omega_{e q}=\sqrt{\sum_{n=1}^{m} \frac{-\left(C_{13} K_{U}+C_{23} K_{V}+C_{33}+C_{34} K_{X}+C_{35} K_{Y}\right)_{m}}{\rho h_{m}}}$

where, $\mathrm{m}$ is the number of variable sections in a curved composite plate. 
$w_{1,2}^{2}=\frac{1}{2}\left(\frac{k_{e q}+k_{2}}{M_{e q}}+\frac{k_{2}}{M_{2}}\right) \mp \sqrt{\frac{1}{4}\left(\frac{k_{e q}+k_{2}}{M_{e q}}+\frac{k_{2}}{M_{2}}\right)^{2}-\frac{k_{e q} k_{2}}{M_{e q} M_{2}}}$

where, $M_{e q}$ is the equivalent mass of the variable thickness plates.

$$
\begin{aligned}
& K_{e q}=\omega_{e q}^{2} M_{e q} \\
& F(t)=K_{2}^{*}\left[\begin{array}{l}
\frac{A_{1}\left(C_{1}-1\right)}{w_{1}^{2}-w_{e q}^{2}}\left(w_{1} \sin w_{e q} t-w_{e q} \sin w_{1} t\right)+ \\
\frac{A_{2}\left(C_{2}-1\right)}{w_{2}^{2}-w_{e q}^{2}}\left(w_{2} \sin w_{e q} t-w_{e q} \sin w_{2} t\right)
\end{array}\right]
\end{aligned}
$$

Additionally the analysis above was extended to curved composite plates with unequal width for variable thicknesses. Details of the geometric design are presented in Figures 5 and 6. This analysis has been carried out for various layups presented in Table 3.

b

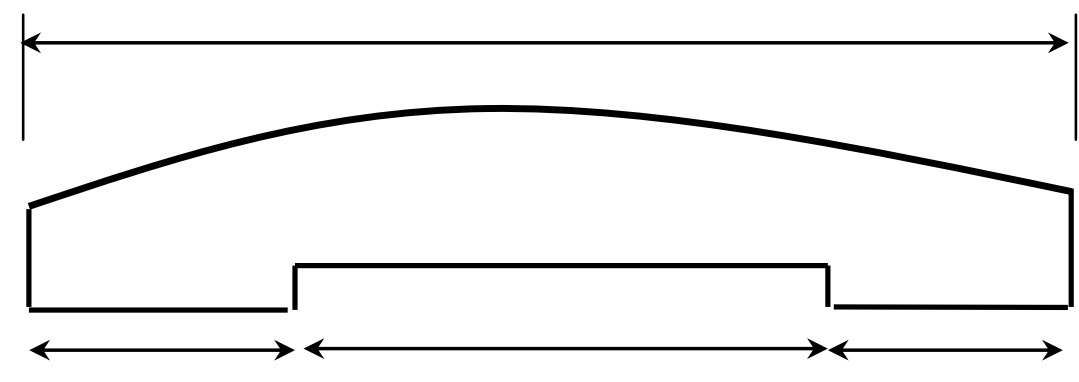
$(1 / 4) b$
$(1 / 2) b$
$(1 / 4) b$

Fig. 5. Three sectioned curved composite plate with variable thicknesses in unequal widths.

$\mathrm{b}$

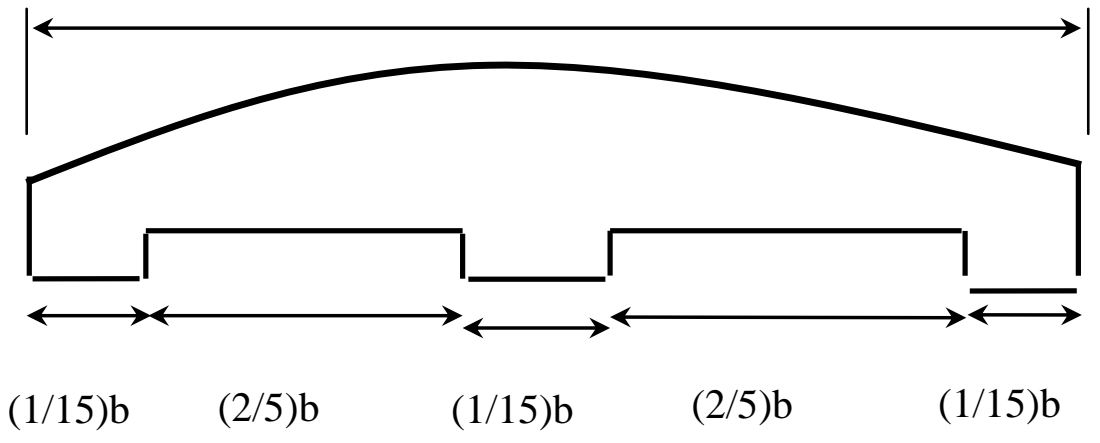

Fig. 6. Five sectioned curved composite plate with variable thicknesses in unequal widths. 


\begin{tabular}{|c|c|c|}
\hline Layup & $\begin{array}{c}\text { Number of } \\
\text { Sections }\end{array}$ & Layup \\
\hline 1 & 3 & $\begin{array}{c}{\left[\begin{array}{lllll}-45 & 45 & 0 & 90 & 0\end{array}\right]_{\mathrm{s}}} \\
{\left[\begin{array}{lllll}-45 & 45 & 0 & 90\end{array}\right]_{\mathrm{s}}} \\
{\left[\begin{array}{lllll}-45 & 45 & 0 & 90 & 0\end{array}\right]_{\mathrm{s}}}\end{array}$ \\
\hline 2 & 3 & $\begin{array}{c}{\left[\begin{array}{lllll}0 & 90 & 0 & 45 & -45\end{array}\right]_{\mathrm{s}}} \\
{\left[\begin{array}{lllll}0 & 90 & -45 & 45\end{array}\right]_{\mathrm{s}}} \\
{\left[\begin{array}{lllll}0 & 90 & 0 & 45 & -45\end{array}\right]_{\mathrm{s}}}\end{array}$ \\
\hline 3 & 3 & 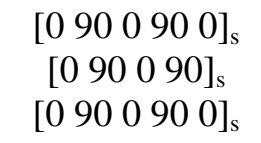 \\
\hline 4 & 5 & $\begin{array}{c}{\left[\begin{array}{lllll}-45 & 45 & 0 & 90 & 0\end{array}\right]_{\mathrm{s}}} \\
{\left[\begin{array}{lllll}-45 & 45 & 0 & 90\end{array}\right]_{\mathrm{s}}} \\
{\left[\begin{array}{lllll}-45 & 45 & 0 & 90 & 0\end{array}\right]_{\mathrm{s}}} \\
{\left[\begin{array}{lllll}-45 & 45 & 0 & 90\end{array}\right]_{\mathrm{s}}} \\
{\left[\begin{array}{lllll}-45 & 45 & 0 & 90 & 0\end{array}\right]_{\mathrm{s}}}\end{array}$ \\
\hline 5 & 5 & $\begin{array}{c}{\left[\begin{array}{lllll}0 & 90 & 0 & 45 & -45\end{array}\right]_{\mathrm{s}}} \\
{\left[\begin{array}{lllll}0 & 90 & -45 & 45\end{array}\right]_{\mathrm{s}}} \\
{\left[\begin{array}{lllll}0 & 90 & 0 & 45 & -45\end{array}\right]_{\mathrm{s}}} \\
{\left[\begin{array}{lllll}0 & 90 & -45 & 45\end{array}\right]_{\mathrm{s}}} \\
{\left[\begin{array}{lllll}0 & 90 & 0 & 45 & -45\end{array}\right]_{\mathrm{s}}}\end{array}$ \\
\hline 6 & 5 & 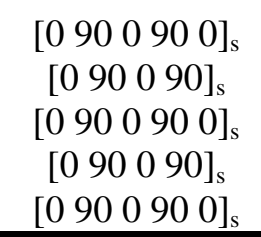 \\
\hline
\end{tabular}

Table 3. Laminate designs of three and five sectioned curved composite plates.

\section{Results and Discussions}

\subsection{Effect of contact stiffness on contact force history}


The analysis on the effect of contact stiffness $k_{2}$ is shown in Figure 7. It can be seen from the model developed in section 5 that the contact force increases with an increase of the contact stiffness, $\mathrm{k}_{2}$, but the contact duration decreases. The higher $k_{2}$ yields to a higher effective contact stiffness, $K_{2}^{*}$. Therefore, a higher contact stiffness between shell and striker indicates more contact force. This means that a larger force is acting over a shorter time period. Likewise, higher modes of deformations are generated due to the shorter contact time.

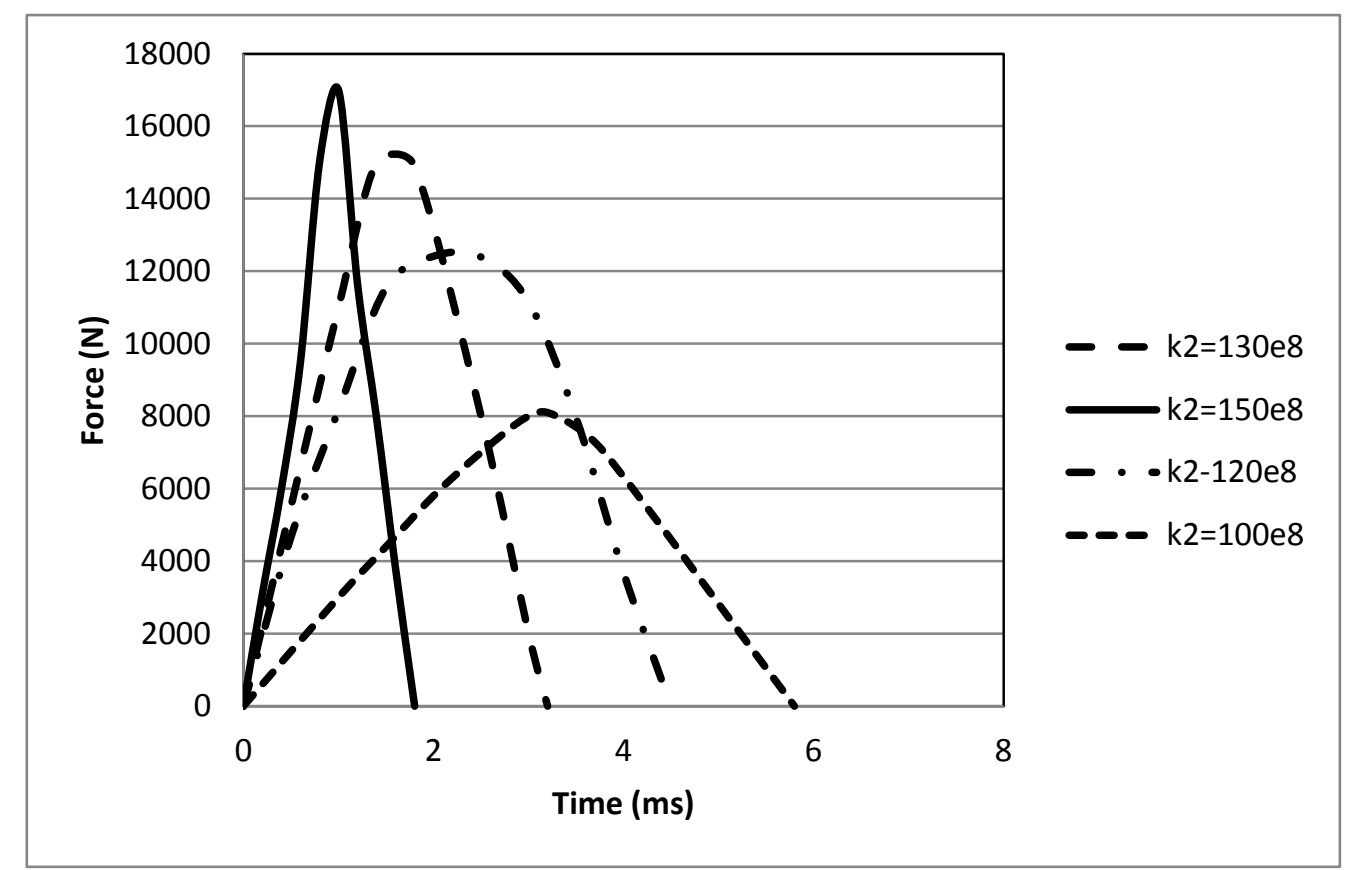

Fig. 7. Effect of contact stiffness on contact force history.

\subsection{Effect of the stacking sequence (Equal widths)}

In this paper the effect of layup and impact velocity was studied for two variable thickness composite plates with three and five sections respectively. Figure 8 shows the effect of fibre orientations and also impact velocity on the contact force history of

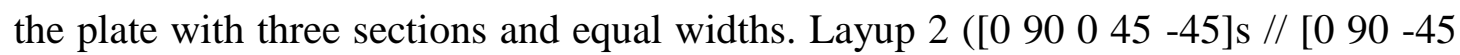
45]s // [ [ $\left.\begin{array}{lllll}0 & 90 & 0 & 4 & -45\end{array}\right] \mathrm{s}$ ) yielded the highest maximum contact force due to the reason that the plate stiffness and natural frequency was higher in this particular orientation. The contact duration for layup 2 is less than the contact time of the other two cases. The maximum contact force for case 2 was 17\% higher than that for layup 1 ([-45 45

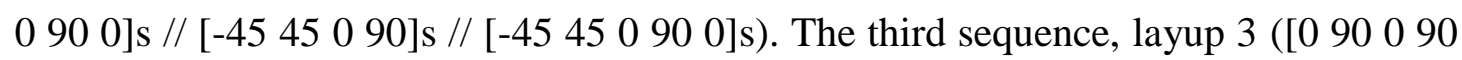


0]s // [ $\left[\begin{array}{llll}0 & 90 & 0 & 90\end{array}\right] \mathrm{s} / /\left[\begin{array}{lllll}0 & 90 & 0 & 90 & 0\end{array}\right] \mathrm{s}$ ) yielded the smallest contact force and was 20\%

1

2

3

4

5

6

7

8

9

10

11

12

13

14

15

16

17

18

19

20

21

22

23

24

25

26

27

28

29

30

31

32

33

34

35

36

37

38

39

40

41

42

43

44

45

46

47

48

49

50

51

52

53

54

55

56

57

58

59

60

61

62

63

64

65 less than the corresponding value of layup 1. 

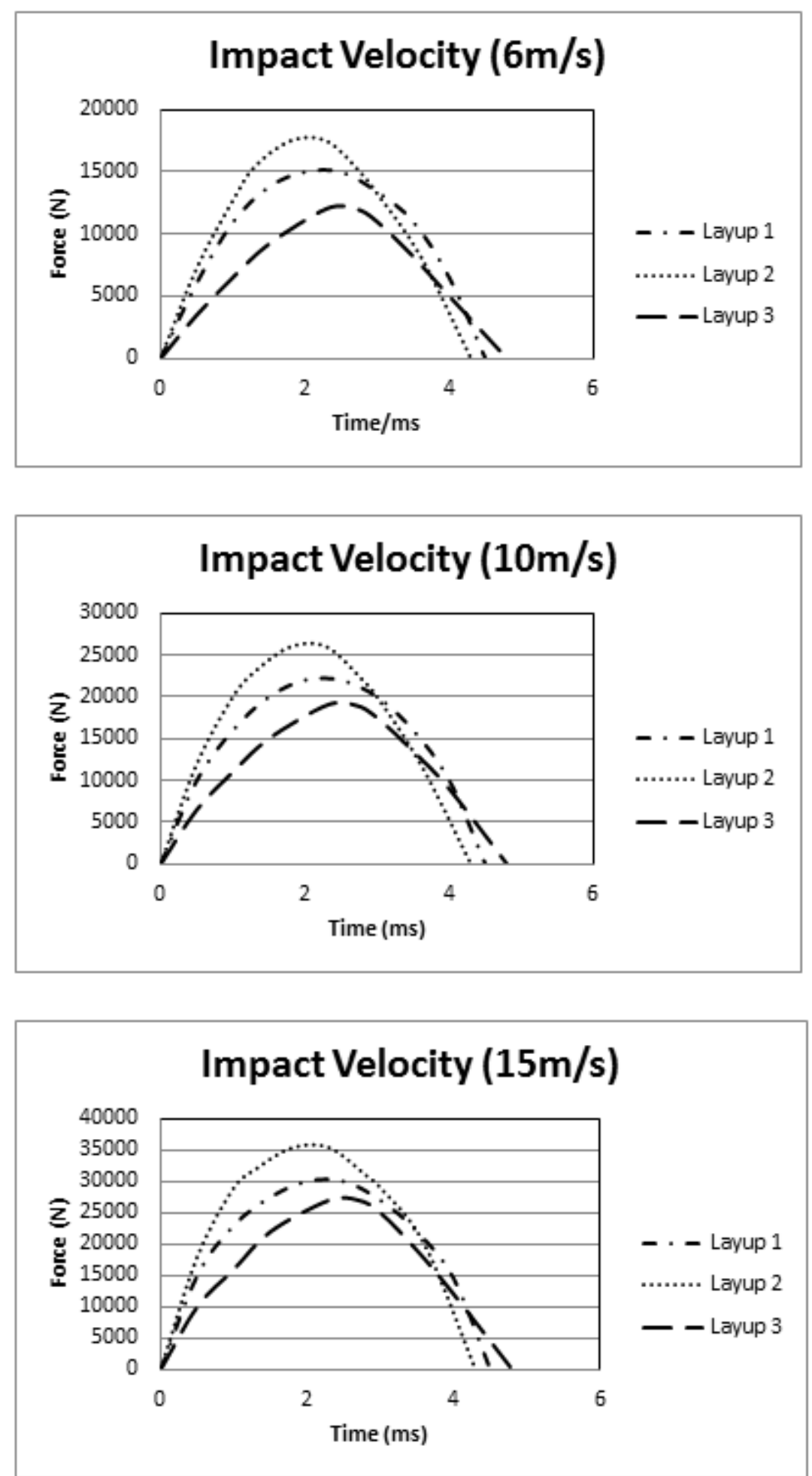

Fig. 8. Effect of stacking sequence on the three sectioned plate with variable thicknesses a) $6 \mathrm{~m} / \mathrm{s}$, b) $10 \mathrm{~m} / \mathrm{s}$ and c) $15 \mathrm{~m} / \mathrm{s}$. 
The contact force of layup 2 was higher than the other two layups, at all values of the impact velocity between $6-15 \mathrm{~m} / \mathrm{s}$. A change of impact velocity from $6-10 \mathrm{~m} / \mathrm{s}$ increased the maximum contact force from $17.5 \mathrm{kN}$ to $26.5 \mathrm{kN}$. It can also be observed from Figure 8(a) and Figure 8(b) that the difference between the maximum contact forces decreases slightly as the impact velocity rises, since an increase of the impact velocity to $15 \mathrm{~m} / \mathrm{s}$ increased the contact force of layup 2 to $35.4 \mathrm{kN}$. This is worthy of note given that the ratios of the kinetic energy of the striker increases much more steeply than the maximum contact force. It is noted that the contact duration remains unchanged.

Figure 9(a) shows the effect of stacking sequence for an impact velocity of $6 \mathrm{~m} / \mathrm{s}$ for a five sectioned plate with variable thicknesses. It can be observed that as the number of sections increased, the effect of stacking sequence decreases.
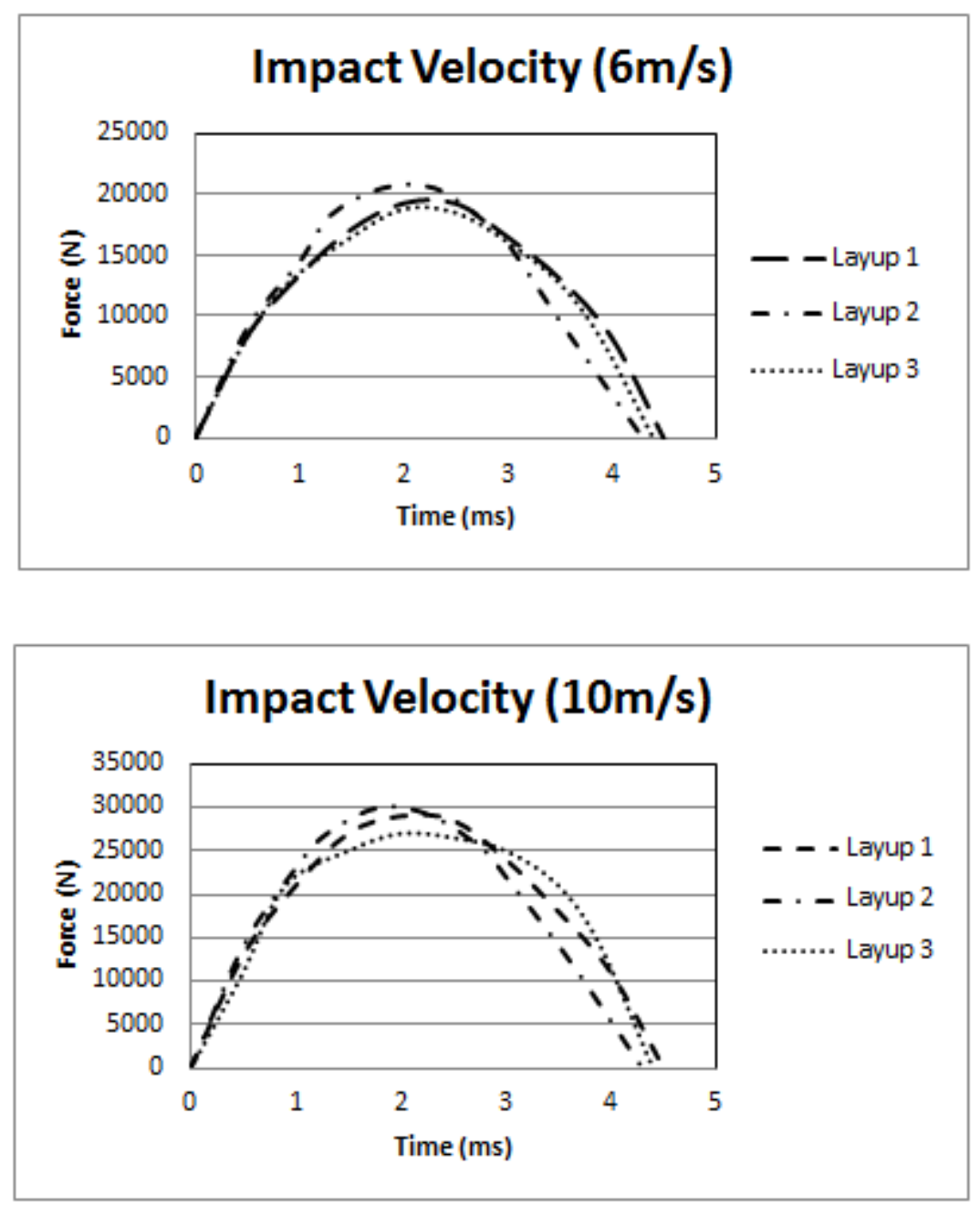


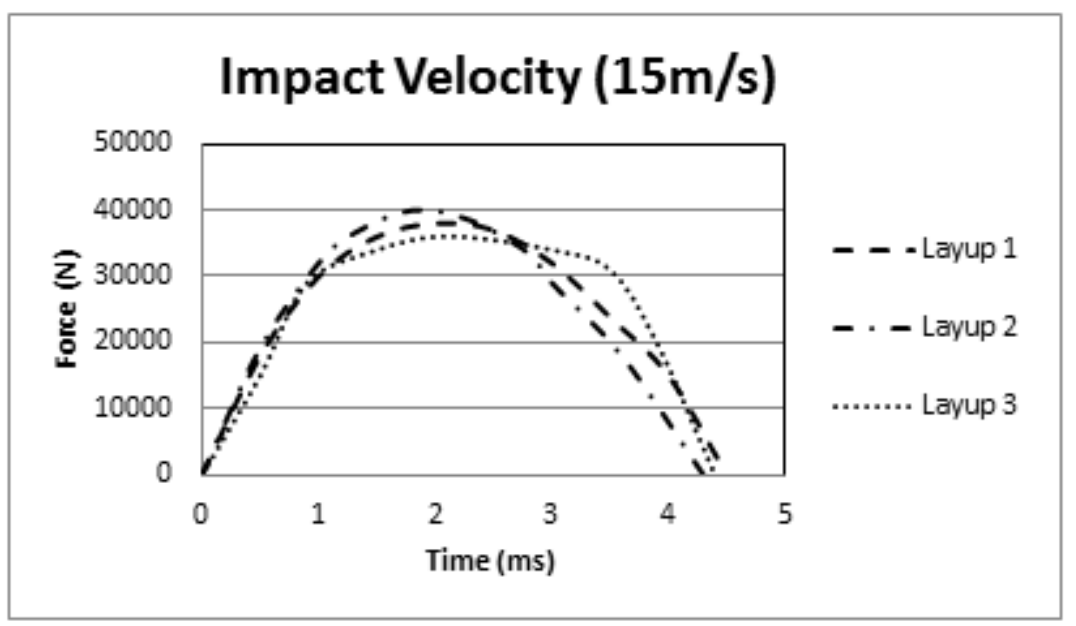

Fig. 9. Effect of stacking sequence on five sectioned plate with variable thicknesses

a) $6 \mathrm{~m} / \mathrm{s} \mathrm{b)} 10 \mathrm{~m} / \mathrm{s}$ and c) $15 \mathrm{~m} / \mathrm{s}$

\subsection{Effect of impact velocity (Equal widths)}

The effect of impact velocity on the contact force is studied in this section. It is observed that the impact velocity has a direct effect on the contact force for all layups. Increasing of impact velocity from $10-15 \mathrm{~m} / \mathrm{s}$ for layup 1 increased the maximum contact force by 36\% as shown in Figure 10(a). The maximum contact force increased by $58 \%$ in layup 3 when the velocity increased from $6-10 \mathrm{~m} / \mathrm{s}$. It is deduced that for all cases accompanied with a three sectioned plate, the increase of contact force was uniform; however, the contact duration remains unchanged. The reason for this is that the higher velocity gives rise to higher impact energy, thus requiring a larger deflection and contact force to dissipate it. 

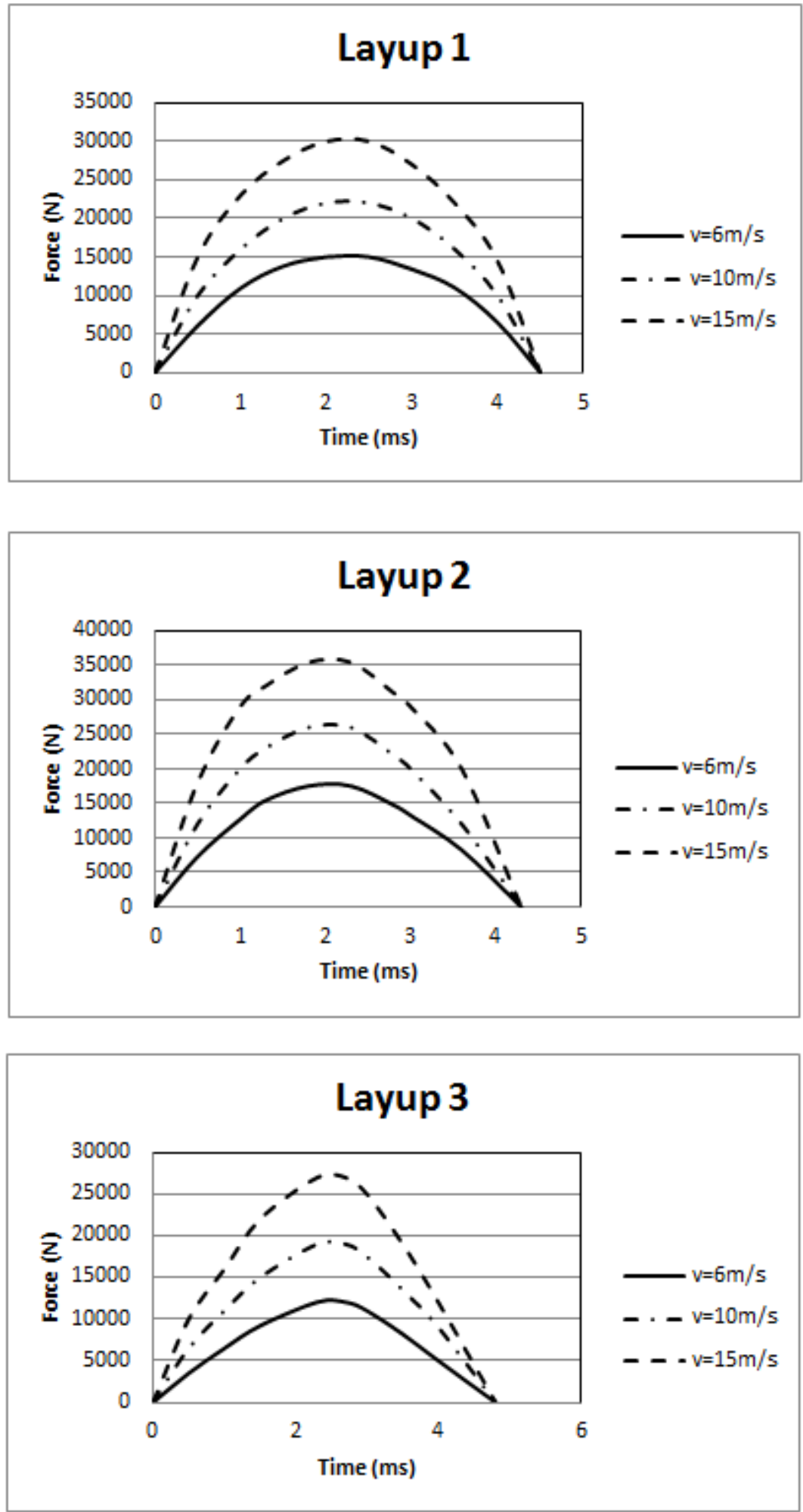

Fig. 10. Effect of impact velocity on a three sectioned plate a) Layup 1 b) Layup 2 and c) Layup 3. 
Figure 11 shows the effect of impact velocity on the composite curved plate with 5 sections for the 3 different layups associated. For example, when the impact velocity was increased from $10-15 \mathrm{~m} / \mathrm{s}$, the maximum impact force increased by $32 \%$ as shown in Figure 11(a) for the fourth stacking sequence (layup 4). This increase was slightly less when compared with the plate with three sections with similar stacking sequence. The greatest increase of maximum contact force for this plate is observed for layup 6 as the impact velocity is raised from $10-15 \mathrm{~m} / \mathrm{s}$. The contact force increased by $33.5 \%$ as observed in Figure 11(c).
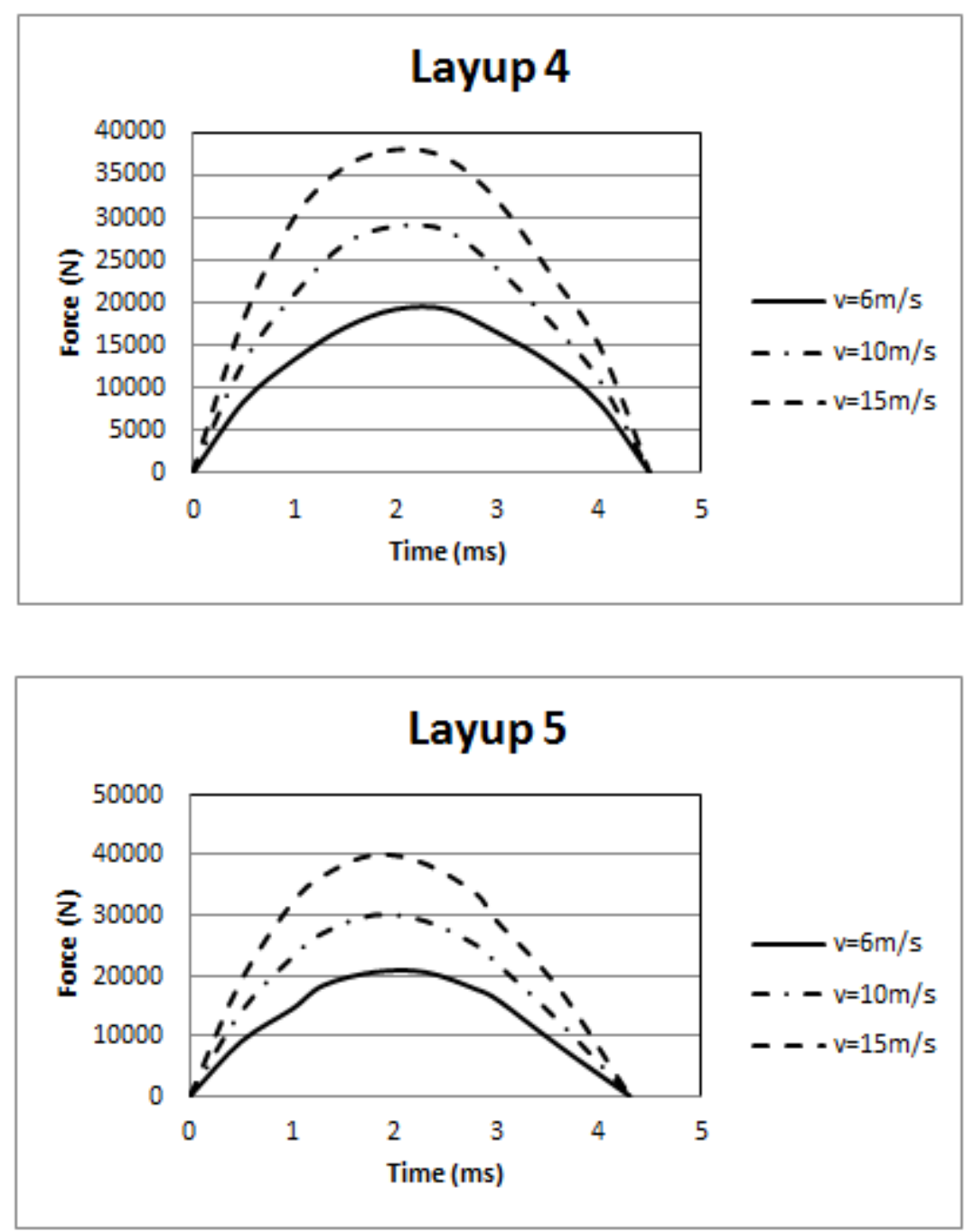


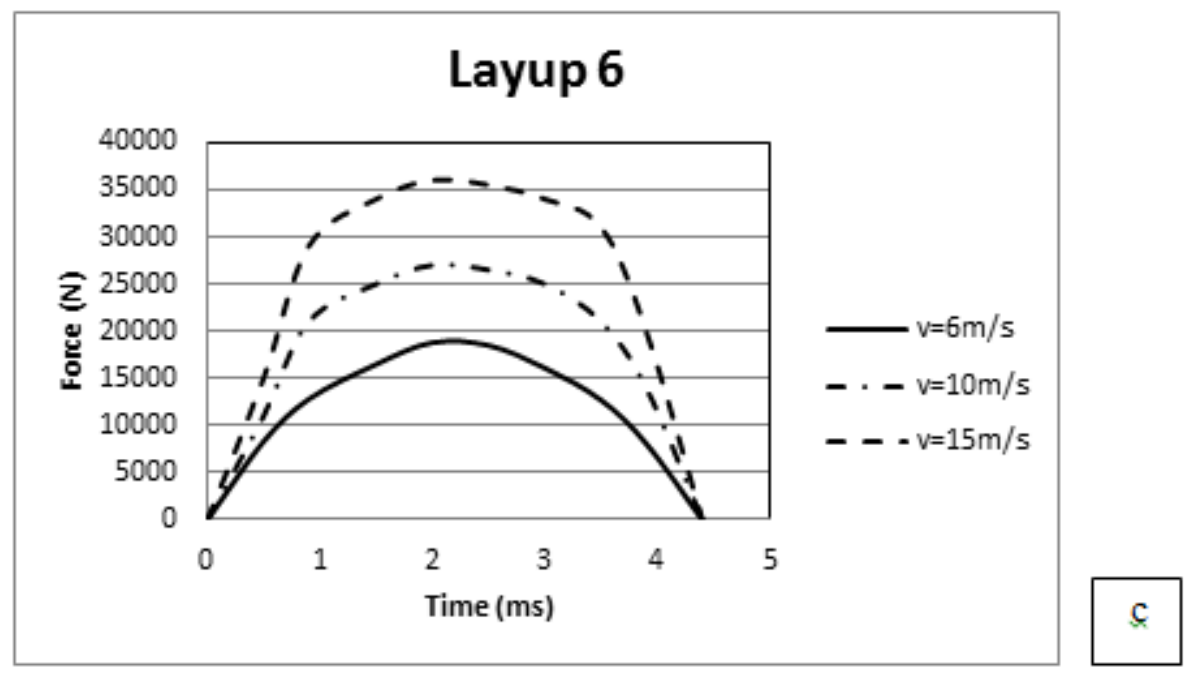

Fig. 11. Effect of impact velocity on five section variable thickness plate a) Layup 4

b) Layup 5 and c) Layup 6.

\subsection{Effect of stacking sequence (un-equal width sections)}

The visual representation depicted by Figures 12 and 13 gives a detailed understanding on the effect of the stacking sequence on the two types of plates. The impact velocity was set at $6 \mathrm{~m} / \mathrm{s}$ in the first instance as shown in Figure 12.

Similarly to the plate with equal widths, layup 2 yielded the maximum contact force for the plate with unequal widths. However, the variation of contact force as the stacking sequence changes remained slightly less affected. For example, as the stacking sequence is changed from the first case to the second; the maximum contact force increased only by $3 \%$, whereas for the plate with equal sections, it was $17 \%$. This fact shows if the number of sections in the panel increases, the effect of stacking sequence on the contact force will decrease. Figure 12 shows the results for the contact force histories with different impact velocities. It is observed that as the velocity increases, the curves tends to be more spread out, thus the difference in maximum contact force between all selected stacking sequences increases. 

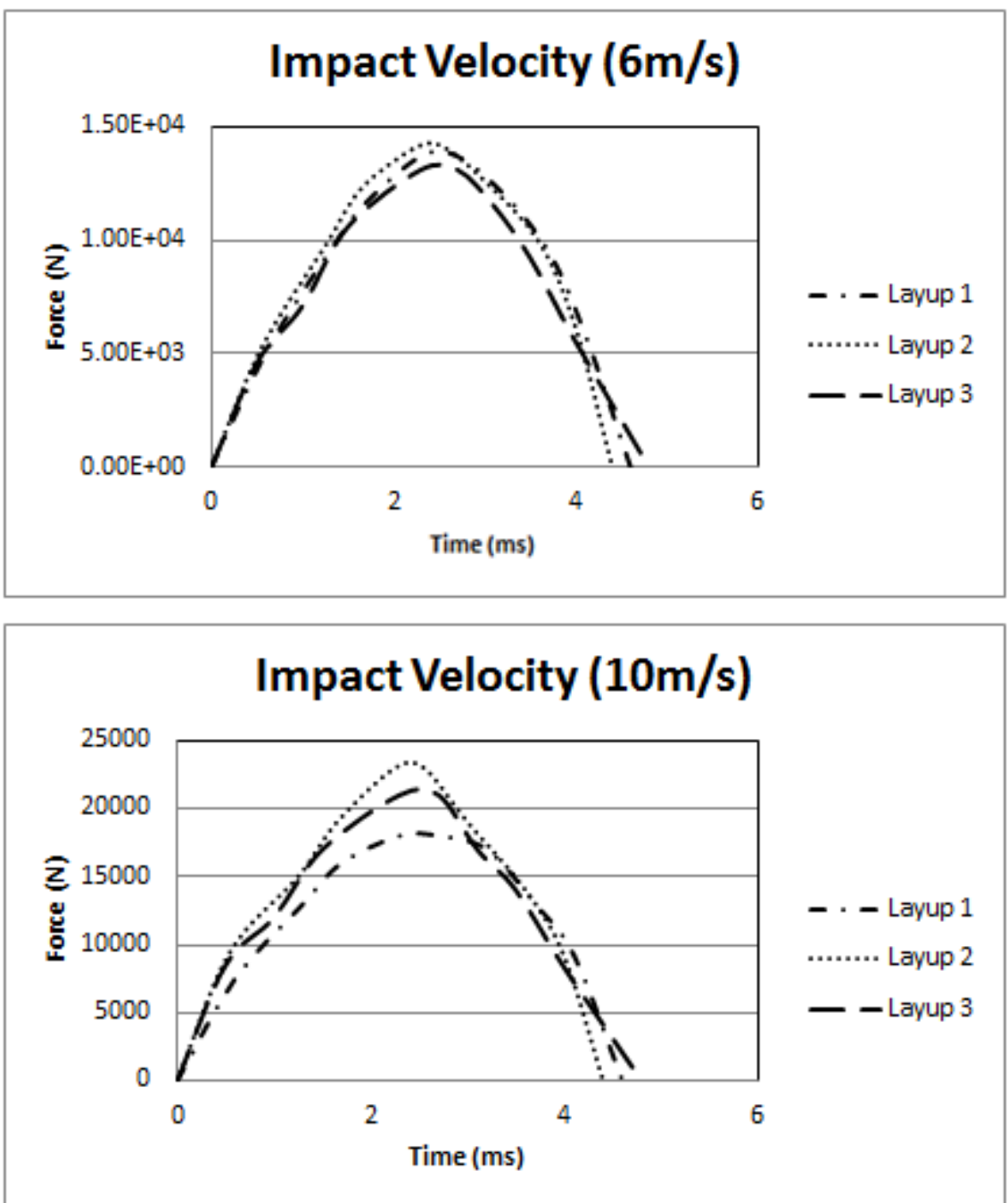

b
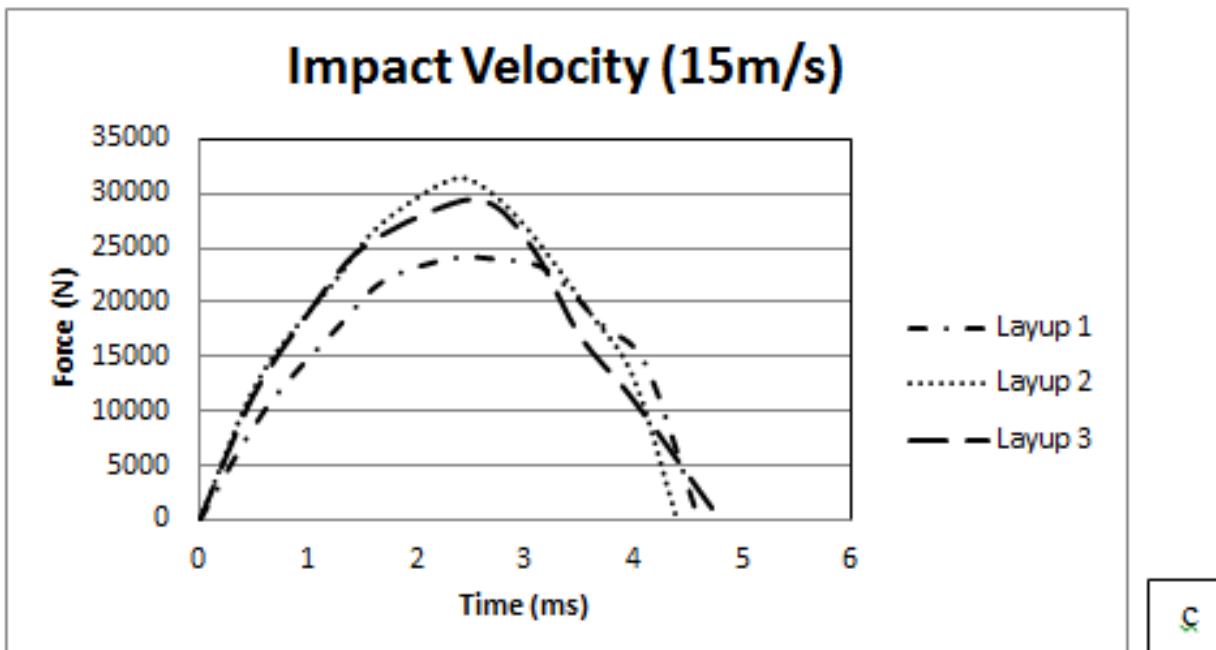

Fig 12. Effect of stacking sequence on three section variable thickness plate with unequal sections a) $6 \mathrm{~m} / \mathrm{s} \mathrm{b}$ ) $10 \mathrm{~m} / \mathrm{s}$ and c) $15 \mathrm{~m} / \mathrm{s}$. 

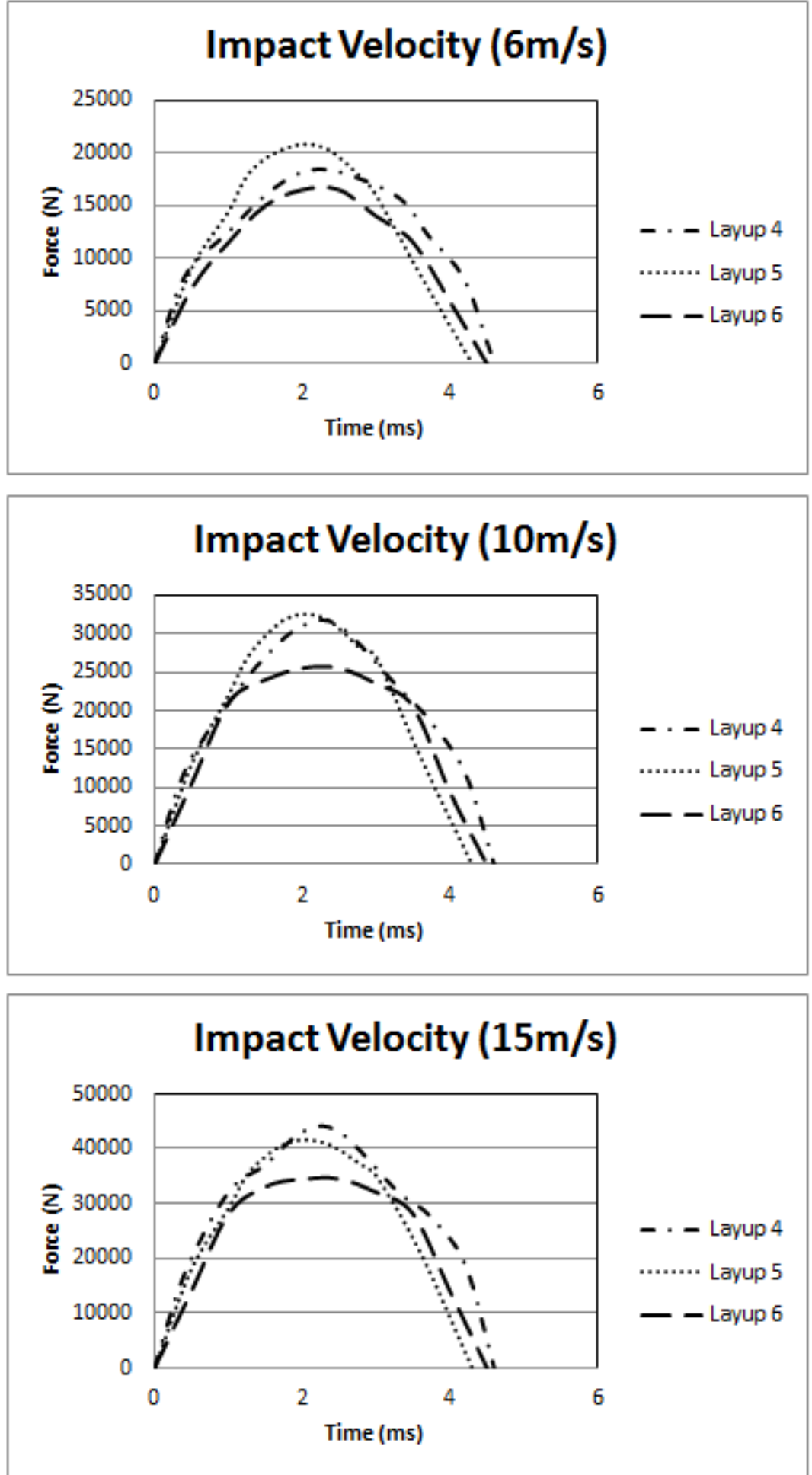

Fig 13. Effect of stacking sequence on a five unequal section plate with variable thicknesses a) $6 \mathrm{~m} / \mathrm{s}$ b) $10 \mathrm{~m} / \mathrm{s}$ and c) $15 \mathrm{~m} / \mathrm{s}$.

A larger effect on the contact force is observed for the 5 section unequal width plate when compared with the 3 section unequal width plate, as shown in Figure 13. An 
increase in the contact force of $12.6 \%$ is depicted when the stacking sequence is changed from layup 4 to 6 . This force was higher when compared with the $3 \%$ increase obtained in the case of the 3 section unequal width plate. Therefore, it can be concluded that as the number of sections increases, the change in maximum contact force also increases. This is different compared to the case of plates of equal sections where the effect of stacking sequence decreased with an increase in the number of sections. Figure 14 shows the variations in the contact force with different striker velocities. In this case, the results showed that the contact force of layup 2 was higher in this instance. 

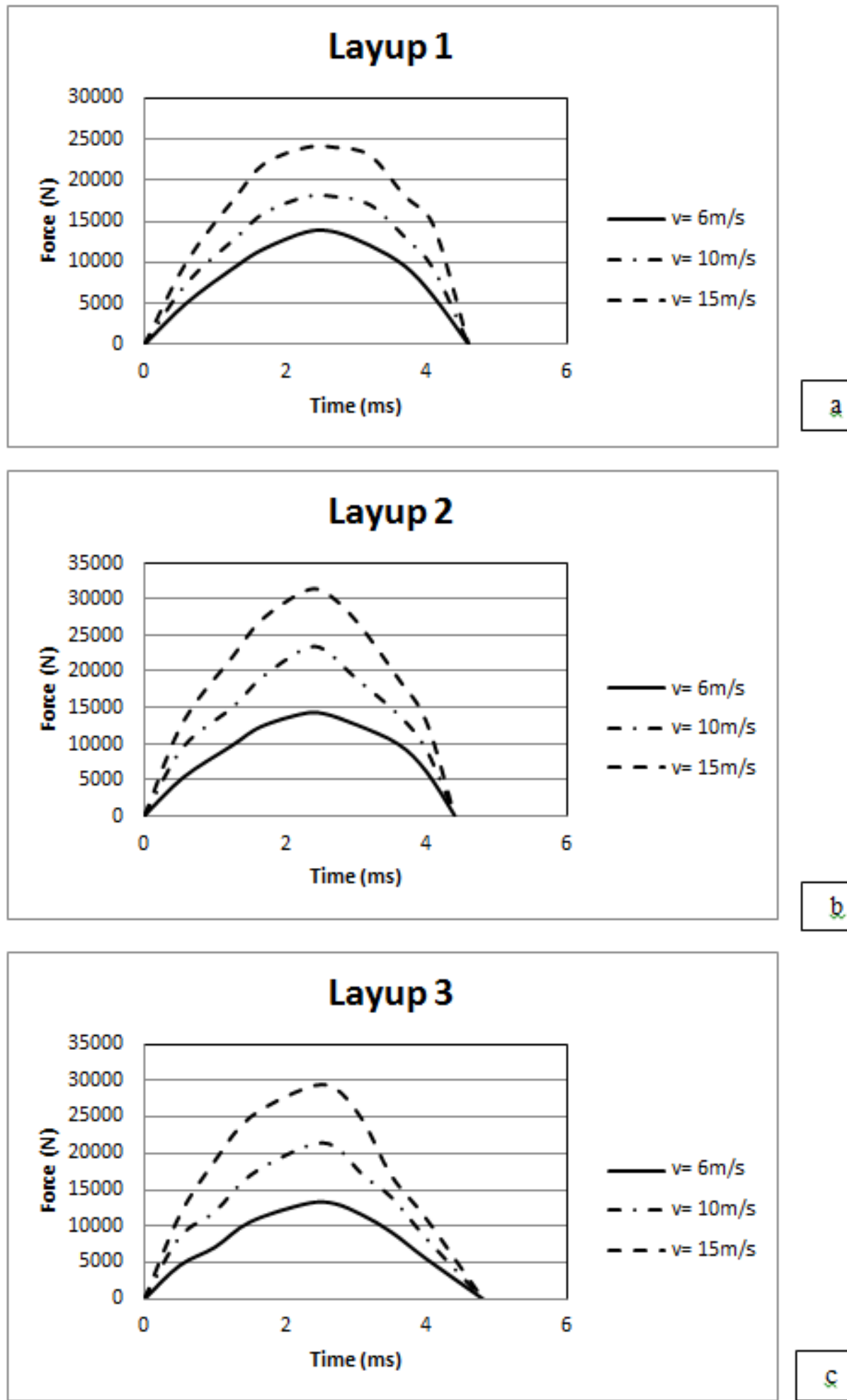

Fig. 14. Effect of stacking sequence on five section variable thickness plate with unequal sections a) $6 \mathrm{~m} / \mathrm{s} \mathrm{b}$ ) $10 \mathrm{~m} / \mathrm{s}$ and c) $15 \mathrm{~m} / \mathrm{s}$. 


\subsection{Effect of impact velocity (un-equal width sections)}

Here we report the effect of impact velocity on the three and five sectioned plate with un-equal widths. Increasing the impact velocity had a direct effect on the contact force as discussed earlier. The maximum contact force increased with an increase of the striker velocity.

Figure 15 shows the effect of the impact velocity on the impact force history of the plate with five sections. Similarly to the previous cases, the maximum impact force increases with an increase in velocity. The largest change in the maximum contact force was observed in layup 5 as the velocity changes from $6-10 \mathrm{~m} / \mathrm{s}$. This change was higher than the change observed for the plate with equal sections.
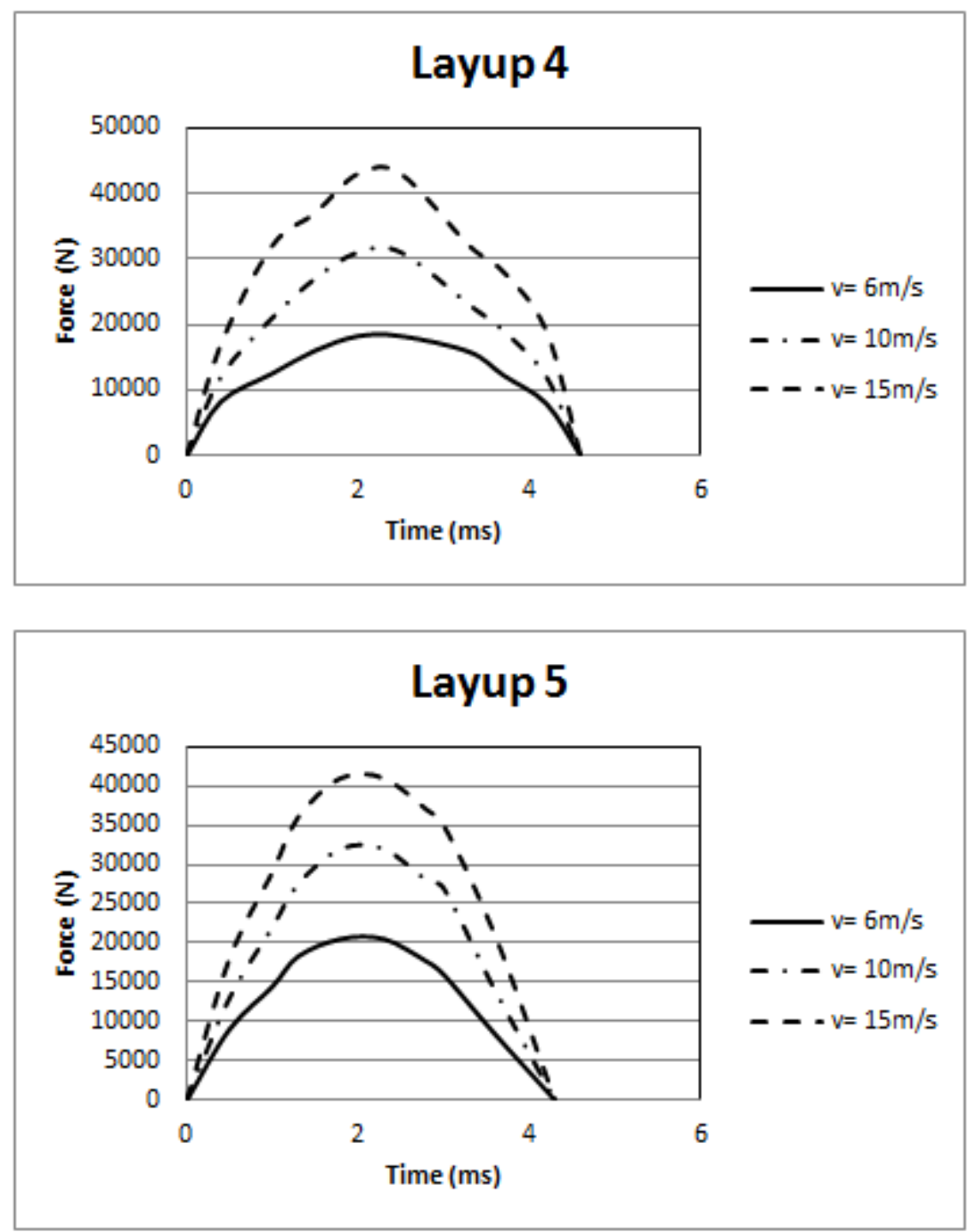


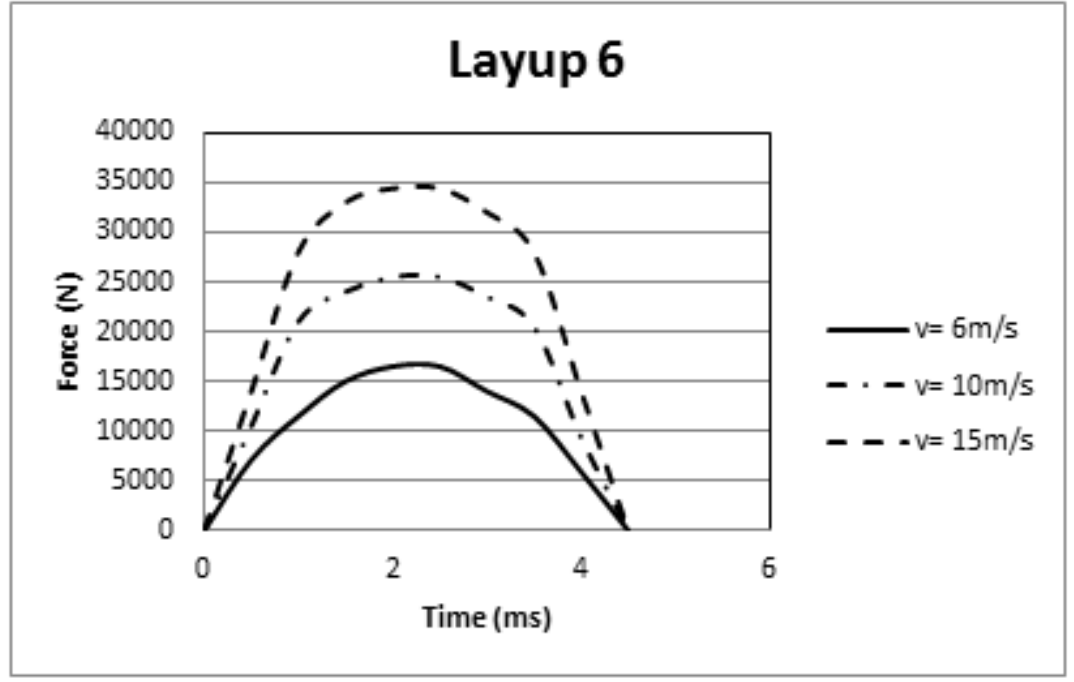

Fig. 15. Effect of impact velocity on five section variable thickness plate with unequal widths a) Layup 4 b) Layup 5 and c) Layup 6.

\section{Conclusions}

In this paper, a mathematical model was developed to predict the impact response of curved fibre-reinforced polymer (FRP) composite plates with variable lateral stiffness which is a more realistic representation of composite structures compared to existing models. The analysis was performed first to validate the original model against available results in the literature and then it was used to study four geometry designs with variable lateral stiffness. The outcomes were presented in the form of force-time history curves and maximum impact forces were calculated for each case. The comparison between all of these designs is summarised in Tables 4 and 5. It is anticipated that this knowledge may benefit the composite industry in providing a better understanding of structural health monitoring and protection mechanisms of advanced composite structures in aerospace and automotive sections. This may help to significantly reduce calculation time during design, analysis and manufacturing as well as improving the quality of final products. 


\begin{tabular}{|c|c|c|c|}
\hline \multirow{2}{*}{ Layup } & \multirow{2}{*}{ Stacking Sequence } & \multicolumn{2}{|c|}{ Max. Contact Force } \\
\hline & & Equal & Unequal \\
\hline 1 & 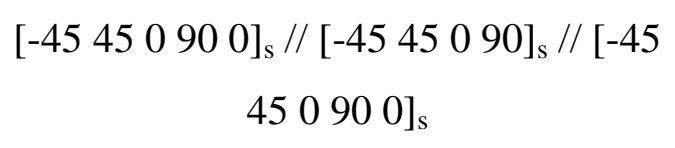 & $15 \mathrm{kN}$ & $13.7 \mathrm{kN}$ \\
\hline 2 & 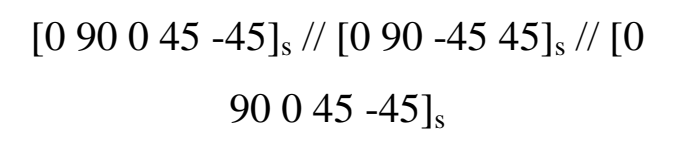 & $17.5 \mathrm{kN}$ & $14.1 \mathrm{kN}$ \\
\hline 3 & $\begin{array}{c}{\left[\begin{array}{lllll}0 & 90 & 0 & 90 & 0\end{array}\right]_{\mathrm{s}} / /\left[\begin{array}{llll}0 & 90 & 0 & 90\end{array}\right]_{\mathrm{s}} / /\left[\begin{array}{llll}0 & 90 & 0\end{array}\right.} \\
90\end{array}$ & $12 \mathrm{kN}$ & $13.1 \mathrm{kN}$ \\
\hline
\end{tabular}

Table 4 Comparison of maximum contact forces for a three sectioned plate with equal and unequal widths.

\begin{tabular}{|c|c|c|c|}
\hline \multirow{2}{*}{ Layup } & \multirow{2}{*}{ Stacking Sequence } & \multicolumn{2}{|c|}{ Max. Contact Force } \\
\hline & & Equal & Unequal \\
\hline 4 & $\begin{array}{c}{\left[\begin{array}{ccccc}-45 & 45 & 0 & 90 & 0\end{array}\right]_{\mathrm{s}} / /\left[\begin{array}{lllll}-45 & 45 & 0 & 90\end{array}\right]_{\mathrm{s}} / /\left[\begin{array}{cccc}-45 \\
45 & 0 & 90 & 0\end{array}\right]_{\mathrm{s}} / /\left[\begin{array}{cccc}-45 & 45 & 0 & 90\end{array}\right]_{\mathrm{s}} / /\left[\begin{array}{llll}-45 & 45 \\
0 & 90 & 0\end{array}\right]_{\mathrm{s}}}\end{array}$ & $19.3 \mathrm{kN}$ & $18.2 \mathrm{kN}$ \\
\hline 5 & 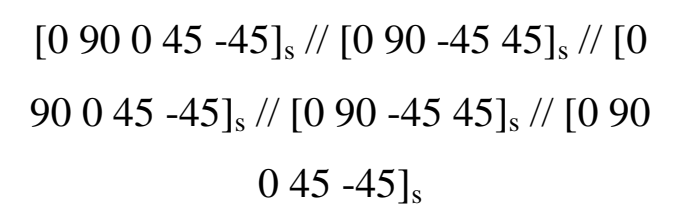 & $20.5 \mathrm{kN}$ & $20.5 \mathrm{kN}$ \\
\hline 6 & 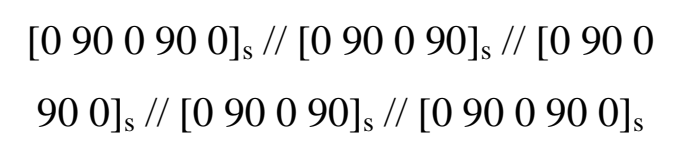 & $18.8 \mathrm{kN}$ & $16.5 \mathrm{kN}$ \\
\hline
\end{tabular}

Table 5. Comparison of the maximum contact forces for the five sectioned plate with equal and unequal widths (// change of thickness). 


\section{References}

[1] Abrate S. (1998) Impact on composites structures. Cambridge University, Press. ASTM D 3171-99, 2002. Standard test method for constituent content of composite materials. Annual book of ASTM standards, West Conshohocken, PA.

[2] Chai GB, Zhu S. A review of low-velocity impact on sandwich structures. Proc Inst Mech Eng Part L: J Mater: Des Appl 2011;225(4):207-30.

[3] Malekzadeh Fard K, Khalili SMR, Forooghy SH, Hosseini M. Low velocity transverse impact response of a composite sandwich plate subjected to a rigid blunted cylindrical impactor. Composites: Part B 63 2014;63:111-122.

[4] Khalili SMR, Ardali A. Low velocity impact response of doubly curved symmetric cross-ply laminated panel with embedded SMA wires. Composite Structures 2013;216-226.

[5] Shivakumar KN, Elber W, Illg W. Prediction of low-velocity impact damage in composite laminates. AIAA J 1984;23(5):442-9.

[6] Gong SW, Lam KY. Effects of structural damping and stiffness on impact response of layered structures. AIAA J 2000;38(9):1730-5.

[7] Gong, S. The elastic response of orthotropic laminated cylindrical shells to lowvelocity impact. Composite Engineering, 1994;4:247-266.

[8] Caprino G, Teti R. Impact and post-impact behaviour of foam core sandwich structures. J Compos Struct 1994;29:47-55.

[9] Anderson TA. An investigation of SDOF models for large mass impact on sandwich composites. Composites: Part B 2005;36:135-42.

[10] Nanda N, Kapuria S. Spectral finite element for wave propagation analysis of laminated composite curved beams using classical and first order shear deformation theories. Compos. Struct, 2015;132:310-320.

[11] Kavousi Sisi M, Shakeri M, Sadighi M. Dynamic response of composite laminated beams under asynchronous/repeated low-velocity impacts of multiple masses. Compos. Struct, 2015;132(15):960-973.

[12] Dinh Duc N. Corrigendum to Nonlinear dynamic response of imperfect eccentrically stiffened FGM double curved shallow shells on elastic foundation. Compos. Struct. 2013;102:306-314. 
[13] Nonlinear dynamic response of imperfect eccentrically stiffened FGM double curved shallow shells on elastic foundation. Composite Structures, 2013(99):8896.

[14] Li DH, Liu Y, Zhang X. Low-velocity impact responses of the stiffened composite laminated plates based on the progressive failure model and the layerwise/solid-elements method. Composite Structures, 2014;110:249-275.

[15] Ghasemnejad H, Soroush VR, Mason PJ, Weager B. To improve impact damage response of single and multi-delaminated FRP composites using natural Flax yarn. Materials and design, 2012;36:865-73.

[16] Ghasemnejad H, Furquan ASM, Mason PJ. Charpy impact damage behaviour of single and multi-delaminated hybrid composite beam structures. Materials \& Design, 2010;31(8): 3653-3660. 